\title{
BMJ Open Prevalence and practice for rare diseases in primary care: a national cross- sectional study in the USA
}

\author{
Ara Jo, ${ }^{1}$ Samantha Larson, ${ }^{1}$ Peter Carek, ${ }^{2}$ Michael R Peabody, ${ }^{3}$ \\ Lars E Peterson, ${ }^{3,4}$ Arch G Mainous ${ }^{1,2}$
}

To cite: Jo A, Larson S, Carek P, et al. Prevalence and practice for rare diseases in primary care: a national cross-sectional study in the USA. BMJ Open 2019;9:e027248. doi:10.1136/ bmjopen-2018-027248

- Prepublication history for this paper is available online To view these files, please visit the journal online (http://dx.doi org/10.1136/bmjopen-2018027248).

Received 15 0ctober 2018 Revised 1 March 2019 Accepted 5 March 2019

\section{Check for updates}

\section{(c) Author(s) (or their} employer(s)) 2019. Re-use permitted under CC BY-NC. No commercial re-use. See rights and permissions. Published by BMJ.

${ }^{1}$ Health Services Research, Management and Policy, University of Florida, Gainesville, Florida, USA

${ }^{2}$ Community Health and Family Medicine, University of Florida, Gainesville, FL, USA

${ }^{3}$ American Board of Family Medicine, Lexington, Kentucky, USA

${ }^{4}$ Family and Community Medicine, University of Kentucky, Lexington, Kentucky, USA

Correspondence to Professor Ara Jo; ara13j@phhp.ufl.edu

\section{ABSTRACT}

Objectives There are more than 7000 rare diseases in the USA, and they are prevalent in $8 \%$ of the population. Due to life-threatening risk and limited therapies, early detection and treatment are critical. The purpose of this study was to explore characteristics of visits for patients with rare diseases seen by primary care physicians (PCPS). Design The study used a cross sectional study using a national representative dataset, the National Ambulatory Medical Care Survey for the years 2012-2014.

Setting Primary care setting.

Participants Visits to PCPs ( $\mathrm{n}=22306$ representing 354 507772 office visits to PCPs).

Primary outcome measures Prevalence of rare diseases in visits of PCPs was the primary outcome. Bivariate analyses and logistic regression analyses were used to compare patients with rare diseases and those without rare diseases and examined characteristics of PCP visits for rare diseases and practice pattern.

Results Among outpatient visits to PCPs, rare diseases account for $1.6 \%$ of the visits. The majority of patients with rare diseases were established patients $(93.0 \%)$ and almost half (49.0\%) were enrolled in public insurance programmes. The time spent in visits for rare diseases (22.4 min) and visits for more common diseases (21.3 min) was not significantly different $(\mathrm{p}=0.09)$. In an adjusted model controlling for patient characteristics (age, sex, types of insurance, reason for this visit, total number of chronic disease, having a rare disease and established or new patient), patients with rare diseases were $52 \%$ more likely to be referred to another provider (OR $1.52,95 \% \mathrm{CI}$, 1.01 to 2.28).

Conclusions Visits for rare diseases are uncommon in primary care practice. Future research may help to explain whether this low level of management of rare diseases in primary care practice is consistent with a goal of a broad scope of care.

\section{INTRODUCTION}

Primary care physicians (PCPs) are trained to provide care for a broad scope of conditions within their patient population. When PCPs maintain a broad scope of practice this safeguards access and quality of care for the general population. Some of these conditions are managed directly by the PCP and

\section{Strengths and limitations of this study}

This study is the first research to investigate characteristics of patients with rare diseases seen in primary care practice and the association between physician referral and rare disease diagnosis.

- The study used population-based national representative data allowing for generalisability.

- Primary care physicians may play a vital role in providing continuous care and managing patients with rare diseases effectively.

- The study is limited to the actions recorded in one visit due to study design.

- The study was unable to determine if that referral is for a consult or part of a shared care relationship between primary care and specialty care.

with others the PCP coordinates the care for the patient. One recent study indicated that in 1 year, family physicians typically manage about 1700 diagnoses in office visits, with 100 diagnoses managed frequently. ${ }^{1}$

In addition to common, high prevalence diseases like diabetes, hypertension and arthritis, a substantial proportion of the general patient population, has a rare disease, or diseases. As of 2017, the National Institute of Health Genetic and Rare Disease (GARD) Information Center had identified 7000 rare diseases, affecting approximately 25-30 million people in the US population. ${ }^{2}$ Rare diseases are categorised as life-threatening, with only few limited effective therapies available. In addition to the emotional and physical burden associated with diagnosis, patients with a rare disease often face financial burden due to the significant cost associated with drugs and therapies. As such, early detection and treatment are critical. For example, in one study, more than half of patients with rare diseases being seen at a PCP practice had been diagnosed with rare diseases at a PCP practice. $^{3}$

However, to date there have been few studies investigating the role of PCPs in the 
management of patients with rare diseases. The purpose of this study was to examine in a nationally representative sample of visits, the prevalence of rare diseases cared for in primary care practice as well as characteristics of patients and providers.

\section{METHODS}

This study used the National Ambulatory Medical Care Survey (NAMCS), a national representative dataset, for the years of 2012 to 2014 . The NAMCS is a national probability sample survey of ambulatory medical care visits to office-based physicians that allows for national estimates regarding medical care in the USA. ${ }^{3}$ Non-federally employed physicians defined by the American Medical Association and the American Osteopathic Association who were principally engaged in patient care activities and who are not specialised in anaesthesiology, pathology and radiology were eligible. Also physicians who are younger than 85 years of age at the time of the survey were eligible. Based on multistage probability design, eligible PCPs were selected and informed about the survey and those who agreed to participate to the survey were included in the data. ${ }^{3}$ NAMCS data are collected annually by the National Center for Health Statistics (NCHS). It is electronic record collected by the Census Bureau in the USA and multiple steps were implemented to process and review the data based on the NCHS protocol. The data estimates to be reliable met two criteria, (1) sample records should be at least 30, and (2) a relative SE should be $30 \%$ or less. ${ }^{3}$ The sample frame for NAMCS data in the years 2012-2014 was composed of PCPs who specialise in primary care (eg, general and family practice, internal medicine and paediatrics), and who identified themselves as the PCP of the patient. ${ }^{4}$ This list conforms to the definition used by the NAMCS to categorise primary care. Diagnosis was determined based upon the International Classification of Diseases (ICD)-9 codes and the diagnosis made by a PCP at a visit was electronically recorded in the patient record form. The patient report form provided pre-existing conditions, current diagnosis and new diagnosis. ${ }^{5}$ Thus, more than 30 diagnoses can be managed via this report form. ${ }^{6}$ Furthermore, this report form allows us to identify established patients who have visited before whereas it does not allow us to estimate numbers of previous visits. The unweighted sample size was 22306 representing 354507772 office visits to PCPs in the USA from 2012 to 2014.

\section{Rare disease}

A rare disease is defined as a disease or a disorder that affects fewer than 200000 people in the USA. ${ }^{27}$ For this study, diagnoses were identified as a rare disease using the list provided by the GARD Information Center. ${ }^{2}$ Two independent researchers and (ie, Dr Jo and Larson) and one family medicine physician (ie, Dr Carek) reviewed all new diagnosis in designated study years and identified rare diseases by comparing the list of GARD. With consensus agreements, rare diseases for the study were determined.

\section{Independent variables}

Demographics of patients seen by PCPs, such as age, gender and race/ethnicity, were used. Gender and race/ ethnicity (ie, non-Hispanic White, non-Hispanic Black, Hispanics and Others) were considered categorical variables whereas age was used as a continuous variable. In addition, their form of health insurance, major reason for the visit and total number of diagnosed chronic diseases were included as categorical variables. Health insurance was stratified into four categories: private insurance, public insurance such as Medicaid and Medicare, self-pay and others. Major reason for the visit was also categorised into four groups: new problems, chronic problems, presurgery or postsurgery care and preventive care.

Providers' characteristics including practice location (ie, urban or rural), referral to other providers (ie, yes or no) were examined. Time spent with providers in primary care setting was compared between patients with rare diseases and those without rare diseases. Time spent with providers in primary care is the length of the time the provider spent with the patient at the office and patient's waiting time to see the provider, receive care from providers and prepare for a patient such as reviewing medical chart or physical examination were excluded. ${ }^{3}$

\section{Statistical analysis}

To account for the complex survey design used in the NAMCS, a weighted variable was used to consider survey design effect. This allows for us to provide national estimates of USA ambulatory healthcare visits to office-based physicians and community health centres. ${ }^{3}$ Also, it allows us to produce national estimates of the ambulatory healthcare use in the USA. ${ }^{3}$ The prevalence of rare disease seen in the primary care office visit was estimated. $X^{2}$ tests were used to compare characteristics of PCPs who care for rare diseases against those who do not. Logistic regression was also employed to examine the association between PCP referral to other providers and patient diagnosis of a rare disease. All analyses were conducted in SAS V.9.4.

\section{Patient and public involvement}

Patients and/or public were not involved in this study.

\section{RESULTS}

The final sample was 22306 representing 354507772 office visits to PCPs in the USA from 2012 to 2014. A total of 1508 PCPs participated to submit data for sample patient visits. Of the total patient visits to a PCP, a rare disease was noted in $1.6 \%$ of those visits. PCPs cared for 177 different rare diseases. Patients with rare diseases were significantly older than those without rare diseases (age difference $=8.3$ years, $p<0.01$ ), while no significant differences were found in the distribution of sex and race/ethnicity (table 1). The majority of patients with rare diseases 
Table 1 Characteristics of patients with rare diseases in primary care, National Ambulatory Medical Care Survey 2012-2014 (unweighted $n=22306$, weighted $n=354507772$ )

\begin{tabular}{|c|c|c|c|}
\hline & $\begin{array}{l}\text { Patients } \\
\text { with rare } \\
\text { diseases } \\
(\%)\end{array}$ & $\begin{array}{l}\text { Patients } \\
\text { without rare } \\
\text { diseases } \\
(\%)\end{array}$ & P value \\
\hline Unweighted sample size & 363 & 21943 & \\
\hline Weighted sample size & 5581791 & 348925981 & \\
\hline Mean age (years) ${ }^{*}$ & 47.7 & 39.4 & $<0.001$ \\
\hline \multicolumn{4}{|l|}{ Sex } \\
\hline Female & 56.4 & 53.8 & 0.44 \\
\hline \multicolumn{4}{|l|}{ Race } \\
\hline Non-Hispanic White & 75.0 & 70.6 & 0.54 \\
\hline Non-Hispanic Black & 8.6 & 10.1 & \\
\hline Hispanics & 11.7 & 14.3 & \\
\hline Others & 4.7 & 5.0 & \\
\hline \multicolumn{4}{|l|}{ Insurance types } \\
\hline Private insurance & 49.3 & 54.6 & 0.15 \\
\hline Public insurance & 47.3 & 40.0 & \\
\hline Self-pay & 1.8 & 3.5 & \\
\hline Other & 1.5 & 1.9 & \\
\hline \multicolumn{4}{|l|}{ Major reasons for this visit* } \\
\hline New problems & 33.7 & 42.6 & 0.002 \\
\hline Chronic problems & 39.0 & 28.7 & \\
\hline $\begin{array}{l}\text { Presurgery/ } \\
\text { postsurgery }\end{array}$ & 27.3 & 28.7 & \\
\hline Preventive care & 0.0 & 0.0 & \\
\hline $\begin{array}{l}\text { Total number of chronic } \\
\text { diseases }\end{array}$ & 1.3 & 1.0 & 0.001 \\
\hline
\end{tabular}

*Statistical significant level at 0.05 .

were established patients $(93.0 \%)$, having been seen by the PCP more than one time, and almost half (49.3\%) were enrolled in private insurance programmes. Of the visits for patients diagnosed with a rare disease, 39.0\% visited their PCPs with a comorbid chronic problem. In addition, they had a significantly higher total number of chronic diseases compared with patients without rare diseases $(\mathrm{p}<0.01)$ (table 1$)$.

Of visits by patients with rare disease, $14.3 \%$ were referred to other providers (table 2). While PCPs spent slightly more time with their patients who had rare diseases (22.4 min), compared with patients without rare diseases (21.3 min), it was not significantly different (table 2 ). The majority of visits for patients with rare diseases and more common diseases who were seen by PCPs were located in urban areas. PCPs practising in rural areas $(7.6 \%)$ were not significantly less likely than PCPs practising in urban areas $(16.8 \% ; \mathrm{p}=0.06)$ to refer patients with rare diseases to another physician. In a bivariate analysis, care for rare
Table 2 Practice characteristics of primary care physicians who care for patients with rare diseases using National Ambulatory Medical Care Survey, 2012-2014

\begin{tabular}{llll}
\hline & $\begin{array}{l}\text { Patients } \\
\text { with rare } \\
\text { diseases }\end{array}$ & $\begin{array}{l}\text { Patients } \\
\text { without rare } \\
\text { diseases }\end{array}$ & P value \\
\hline $\begin{array}{l}\text { Practising area } \\
\quad \text { Urban }\end{array}$ & 84.5 & 86.4 & 0.32 \\
$\quad$ Rural & 15.5 & 13.6 & \\
$\begin{array}{l}\text { Referral to other } \\
\text { providers* }\end{array}$ & & & \\
$\quad$ Yes & 14.3 & 9.0 & 0.01 \\
$\quad$ No & 85.7 & 91.0 & \\
\hline $\begin{array}{l}\text { Time spent with } \\
\text { providers (min) }\end{array}$ & 22.4 & 21.3 & 0.09 \\
\hline
\end{tabular}

*Statistical significant level at 0.05 .

disease was also not associated with rurality $(\mathrm{p}=0.32)$ (table 2).

In an unadjusted regression model, patients with rare diseases were $69 \%$ more likely to be referred to other providers than those without rare diseases. After controlling for covariates, such as patients' characteristics (ie, age, sex, race/ethnicity, types of insurance, major reason for this visit, total number of chronic disease, having a rare disease and established or new patient), patients with rare diseases were $52 \%$ more likely to be referred to another provider than those without rare diseases (table 3).

\section{DISCUSSION}

This study found that few patients with a rare disease were identified as being managed in primary care practice. Patients with rare diseases in the primary care setting show significantly older and have more comorbidities compared with those without a rare disease diagnosis whereas patients with rare diseases are comparable to those without rare diseases in terms of sex distribution, race/ethnicity and types of health insurance. Not

Table 3 ORs of referral using unadjusted and adjusted logistic regression analyses using National Ambulatory Medical Care Survey, 2012-2014

\begin{tabular}{lll}
\hline & $\begin{array}{l}\text { Unadjusted OR } \\
(\mathbf{9 5 \%} \mathbf{C l})\end{array}$ & $\begin{array}{l}\text { Adjusted OR } \\
(\mathbf{9 5 \%} \mathbf{C l})\end{array}$ \\
\hline $\begin{array}{l}\text { Not having a rare } \\
\text { disease }\end{array}$ & Reference & Reference \\
$\begin{array}{l}\text { Having a rare } \\
\text { disease }\end{array}$ & $1.69(1.15 \text { to } 2.48)^{\star}$ & $1.52(1.01 \text { to } 2.28)^{\star} \dagger$ \\
\hline
\end{tabular}

*Statistical significant level at 0.05 .

†Controlled for age, gender, race/ethnicity, types of insurance, major reason for this visit, total number of chronic disease, having a rare disease and established versus new patient. 
surprisingly, visits in primary care for patients diagnosed with rare diseases are more likely than patients without rare diseases to lead to referral to another provider. To our knowledge, this is the first study to investigate characteristics of patients with rare diseases seen in primary care practice and the association between physician referral and rare disease diagnosis.

Much of medical practice and the corresponding comfort in diagnosing and treating conditions is affected by the frequency of occurrence of the condition and pattern recognition. Rare diseases are by their very nature uncommon and thus PCPs may not always feel comfortable with the nuances of treatment and potential complications for a disease that they encounter very infrequently. According to the National Academy of Medicine, since rare diseases tend to accompany multiple common conditions, it disrupts a clinician's ability to recognise clues of rare diseases. ${ }^{8}$ In many of these cases PCPs need more than a consult from a specialist, especially when the primary care team does not have the specialised medical knowledge. Receiving all of their care from specialists may not be the best situation for the patient. Patients with rare diseases need to be managed in primary care or at least have shared care between primary care and specialists in complementary roles to provide a more effective management of these complex patients.

There are some limitations to this study. First, due to the design of the NAMCS we are limited to the actions recorded in that one visit. The design does allow us to have an understanding of the types of patients seen in primary care but it is not data on a cohort of patients. Thus, we do not know what sort of care may have transpired between the patient and the physician in previous visits. Also, it is not able to explore the linkage of multiple consultations with specialists previsit or postvisit to PCPs. Second, we are able to see if patients are referred in that one visit, we are unable to determine if that referral is for a consult or part of a shared care relationship between primary care and specialty care.

\section{CONCLUSION}

This study identified characteristics of patients with rare diseases who are seen in primary care practice and the delivery patterns of PCPs managing patients with rare diseases. Findings from this study suggest that PCPs must possess a broad scope of practice in order to deliver comprehensive, high-quality care. A better understanding of the overall management of patients with rare diseases managed solely outside of primary care would help to improve the care for these patients.

Contributors AJ led the entire research as the first and corresponding author from writing the manuscript, analysing the data and interpretation. SL analysed the data and contributed to writing the manuscript. PC, MRP, LEP contributed to writing the manuscript. AGM contributed to writing the manuscript and guided the direction of the study.

Funding This work was supported by a grant from the American Board of Family Medicine Foundation.

Competing interests LEP and MRP are employees of the American Board of Family Medicine.

Patient consent for publication Not required.

Ethics approval This study was approved as exempt by the Institutional Review Board at the University of Florida.

Provenance and peer review Not commissioned; externally peer reviewed.

Data sharing statement The NAMCS data are publicly available at https://www. cdc.gov/nchs/ahcd/ahcd_questionnaires.htm.

Open access This is an open access article distributed in accordance with the Creative Commons Attribution Non Commercial (CC BY-NC 4.0) license, which permits others to distribute, remix, adapt, build upon this work non-commercially, and license their derivative works on different terms, provided the original work is properly cited, appropriate credit is given, any changes made indicated, and the use is non-commercial. See: http://creativecommons.org/licenses/by-nc/4.0/.

\section{REFERENCES}

1. Peabody MR, O'Neill TR, Stelter KL, et al. Frequency and criticality of diagnoses in family medicine practices: From the National Ambulatory Medical Care Survey (NAMCS). J Am Board Fam Med 2018;31:126-38.

2. GARD. FAQs About rare diseases: National center for advancing translational sciences. $2017 \mathrm{https}$ ///rarediseases.info.nih.gov/ diseases/pages/31/faqs-about-rare-diseases.

3. Phillips WR. Zebras on the commons: rare conditions in family practice. J Am Board Fam Pract 2004;17:283-6.

4. NCHS. NAMCS Scope and sample design: Centers for disease control and prevention. 2015; https://www.cdc.gov/nchs/ahcd/ahcd_scope. htm.

5. NHCS. NAMCS micro-data file documentation. Centers for Disease Control and Prevention 2014.

6. NCHS. National Ambulatory Medical Care Survey. 2018 https://www. cdc.gov/nchs/data/ahcd/2018_NAMCS_Patient_Record_Sample_ Card.pdf.

7. US Food \& Drug Administration (FDA). Orphan Drug Act - Relevant Excerpts. 2013 https://www.fda.gov/forindustry/developingproduc tsforrarediseasesconditions/howtoapplyfororphanproductdesignation/ ucm364750.htm.

8. Boat TF, Field MJ. Rare diseases and orphan products: Accelerating research and development: National Academies Press, 2011. 